\title{
HIDRÓLISE ENZIMÁTICA DA MICROALGA Chlorella pyrenoidosa
}

\author{
M. F. S. MOTA ${ }^{1}$, M. F. SOUZA ${ }^{1}$, M. A. RODRIGUES ${ }^{2}$, S. P. FREITAS ${ }^{1}$, E. P. S. BON ${ }^{2}$ \\ ${ }^{1}$ Universidade Federal do Rio de Janeiro, Escola de Química \\ ${ }^{2}$ Universidade Federal do Rio de Janeiro, Instituto de Química \\ E-mail para contato: nandaffcmota@gmail.com
}

RESUMO - As microalgas possuem uma composição química diversificada, podendo ser boas fontes de lipídios, carboidratos, proteínas, pigmentos e carotenoides, dependendo da espécie. A hidrólise enzimática é um método para obtenção de açúcares redutores e pode ser utilizada como uma etapa preliminar na obtenção de compostos de interesse a partir da biomassa algal. Nesse trabalho, Chlorella pyrenoidosa, uma alga verde que apresenta parede celular rica em carboidratos, foi submetida à hidrólise enzimática usando celulases fúngicas e enzimas acessórias para produzir açúcares monoméricos. Foram realizados experimentos utilizando os sobrenadantes de culturas individuais de Aspergillus awamori, Trichoderma harzianum 422 e Trichoderma reesei RUT C30 com diferentes proporções de $\beta$-glicosidase e FPase. A biomassa algal foi submetida à hidrólise em sua forma íntegra e após tratamento em moinho de bola. Todos os preparados enzimáticos apresentaram rendimentos em glicose próximos de $60 \%$ e $94 \%$ após $6 \mathrm{~h}$ e $48 \mathrm{~h}$, respectivamente, para a biomassa tratada em moinho de bola. Entretanto, nos experimentos com o material não tratado, o maior rendimento de glicose encontrado foi de $53,76 \%$ em $24 \mathrm{~h}$ utilizando apenas enzimas de A. awamori após redução de carga enzimática e aumento da carga de sólidos. Esses resultados comprovam que o preparado enzimático de Aspergillus awamori é o mais indicado para a hidrólise enzimática da biomassa algal e que o tratamento por moinho de bola é eficaz para essa biomassa.

\section{INTRODUÇÃO}

As microalgas tem sido alvo de diversos estudos para produção de biocombustíveis e bioprodutos por apresentar vantagens como: alto rendimento em biomassa e concentração lipídica elevada; não competir com a produção de alimentos, uma vez que não necessita de terras aráveis; não necessitar de água potável (Sheehan, 2009). Além disso, as microalgas podem ser utilizadas para a captura de carbono, podendo reduzir os níveis de $\mathrm{CO}_{2}$ na atmosfera.

A utilização da biomassa algal vai ao encontro do conceito de biorrefinaria, onde a biomassa deve ser aproveitada integralmente, sendo utilizada para a produção de biocombustíveis, como biodiesel e bioetanol, e para a extração de compostos de alto valor agregado, como a clorofila, os carotenoides e proteínas (Spolaore et al., 2006). A integração desses processos é essencial para a viabilização da produção e a redução dos custos dos derivados de microalgas (Powell e Hill, 2009). 
A hidrólise enzimática tem sido demonstrada como um bom método para obtenção de açúcares redutores e pode ser utilizada como uma etapa preliminar na obtenção de compostos de interesse a partir da biomassa algal. No entanto, devido ao alto custo das enzimas, uma etapa de pré-tratamento pode ser necessária para aumentar os rendimentos de hidrólise e, consequentemente, a viabilidade do processo.

Esse trabalho tem como objetivo avaliar a hidrólise enzimática da microalga Chlorella pyrenoidosa antes e depois de pré-tratamento em moinho de bola, com enzimas produzidas por Trichoderma reesei RUT C30, Aspergillus awamori, Trichoderma harzianum 422 e misturas com diferentes cargas de $\beta$-glicosidase e celulases.

\section{MATERIAIS E MÉTODOS}

\subsection{Composição em Carboidratos da Biomassa}

A determinação da composição da parede celular da microalga Chlorella pyrenoidosa foi realizada através de hidrólise ácida, utilizando o método descrito pelo NREL (Van Wychen \& Laurens, 2013) e o método descrito por Northcote et al. (1958).

\subsection{Tratamento em Moinho de Bola}

O tratamento por moinho de bola foi realizado em um moinho vibratório (Fritsch, Alemanha) contendo 1 bola com amplitude 1,5 por 90 minutos.

\subsection{Hidrólise Enzimática}

Avaliação do pré-tratamento em moinho de bola: Ensaios de hidrólise enzimática com $5 \%$ de carga de sólidos utilizando a biomassa antes e depois do pré-tratamento em moinho de bola foram conduzidos com 5 cargas enzimáticas diferentes: A. awamori e T. reesei RUT C30 com $10 \mathrm{FPU}$ e 20 e $30 \mathrm{BGU} / \mathrm{g}$ biomassa, $A$. awamori com 20 e $30 \mathrm{BGU} / \mathrm{g}$ biomassa e $T$. reesei $\mathrm{RUT}$ C30 com $10 \mathrm{FPU} / \mathrm{g}$ biomassa.

Comparação entre T. reesei RUT C30 e T. harzianum 422: Para a biomassa íntegra, ou seja, antes do pré-tratamento por moagem, foi realizado um ensaio hidrolítico comparando a eficiência das enzimas produzidas pelos fungos Trichoderma reesei RUT C30 e Trichoderma harzianum 422. Os experimentos foram realizados com 5\% de carga de sólidos e $5 \mathrm{FPU} / \mathrm{g}$ de glucana (carga minimizada após ensaios realizados em outro trabalho). Foram testadas 4 cargas enzimáticas diferentes: $A$. awamori e $T$. reesei RUT C30 com $20 \mathrm{BGU} / \mathrm{g}$ de glucana, $A$. awamori e T. harzianum $422 \mathrm{com} 20 \mathrm{BGU} / \mathrm{g}$ de glucana, T. reesei RUT C30 e T. harzianum 422.

Comparação entre A. awamori e T. harzianum 422: Foi realizado um experimento com a biomassa íntegra comparando os perfis hidrolíticos obtidos com enzimas de A. awamori e $T$. harzianum 422 com mesma carga de $\beta$-glicosidase. Os experimentos foram conduzidos com $54 \mathrm{BGU} / \mathrm{g}$ de glucana e $25 \%$ de carga de sólidos (condições otimizadas por planejamento experimental realizado em outro trabalho). 
Todos os experimentos de hidrólise foram conduzidos com uma massa total de $25 \mathrm{~g}$ a $50^{\circ} \mathrm{C}, 200 \mathrm{rpm}$ e pH 4,8 em tampão citrato de sódio $50 \mathrm{mM}$. A determinação de glicose ao longo da hidrólise enzimática foi realizada em analisador bioquímico YSI 2700.

\section{RESULTADOS E DISCUSSÕES}

\subsection{Composição em Carboidratos da Biomassa}

A composição de carboidratos da biomassa determinada por dois métodos baseados em hidrólise ácida encontra-se representada na Tabela 1. Os valores correspondem às médias das triplicatas independentes.

Tabela 1 - Comparação da composição de carboidratos da Chlorella pyrenoidosa determinado pelo método NREL e pelo método de Northcote et al. (1958)

\begin{tabular}{|l|c|c|c|c|c|}
\hline Carboidratos & \multicolumn{1}{|c|}{$\begin{array}{c}\text { Glicose } \\
(\mathbf{\%})\end{array}$} & $\begin{array}{c}\text { Xilose } \\
\mathbf{( \% )}\end{array}$ & $\begin{array}{c}\text { Galactose } \\
\mathbf{( \% )}\end{array}$ & $\begin{array}{c}\text { Arabinose } \\
\mathbf{( \% )}\end{array}$ & $\begin{array}{c}\text { Manose } \\
\mathbf{( \% )}\end{array}$ \\
\hline $\begin{array}{l}\text { Método } \\
\text { NREL }\end{array}$ & $9,301 \pm 0,080$ & $0,339 \pm 0,005$ & $3,622 \pm 0,039$ & $1,105 \pm 0,004$ & $0,558 \pm 0,017$ \\
\hline $\begin{array}{l}\text { Método } \\
\text { Northcote }\end{array}$ & $8,327 \pm 0,461$ & $0,266 \pm 0,029$ & $3,052 \pm 0,145$ & $1,009 \pm 0,065$ & $0,417 \pm 0,041$ \\
\hline
\end{tabular}

As duas metodologias geraram caracterizações parecidas, porém o método NREL gerou valores percentuais de carboidratos maiores e menores desvios-padrão. Essa diferença se deve, possivelmente, à etapa de homogeneização do ácido com a biomassa existente nesse método, o que promove uma maior interação ácido-biomassa e uma hidrólise mais completa.

A caracterização dos carboidratos da biomassa comprova a necessidade de enzimas celulolíticas para a hidrólise dessa biomassa, já que a glicose foi o açúcar mais abundante.

\subsection{Hidrólise Enzimática}

Os rendimentos de glicose dos testes de hidrólise enzimática realizados com carga de 10 FPU/g de biomassa estão descritos na Figura 1, em que as linhas contínuas representam a hidrólise enzimática da microalga moída e as linhas pontilhadas representam a hidrólise da microalga íntegra.

Pode-se notar que o pré-tratamento em moinho de bolas aumentou significativamente o rendimento da hidrólise enzimática. Observa-se também que, para a hidrólise dessa biomassa, não é necessário a presença de exoglucanases (enzimas que atuam na região cristalina da celulose), uma vez que a preparação enzimática de $A$. awamori, rica principalmente em $\beta$ glicosidase, gerou rendimentos similares à preparação enzimática de $T$. reesei-A.awamori. Já para a biomassa íntegra, a mistura $T$. reesei-A.awamori gerou rendimentos maiores.

O aumento de rendimento da hidrólise enzimática causado pelo pré-tratamento em moinho de bola ocorreu, provavelmente, devido ao aumento da área superficial, melhorando a interação das enzimas com o substrato. 
Figura 1 - Rendimento de glicose para hidrólise enzimática da biomassa algal antes (linhas pontilhadas) e depois (linhas cheias) do pré-tratamento em moinho de bola com enzimas do $T$. reesei RUT C30, A. awamori e misturas de ambas.

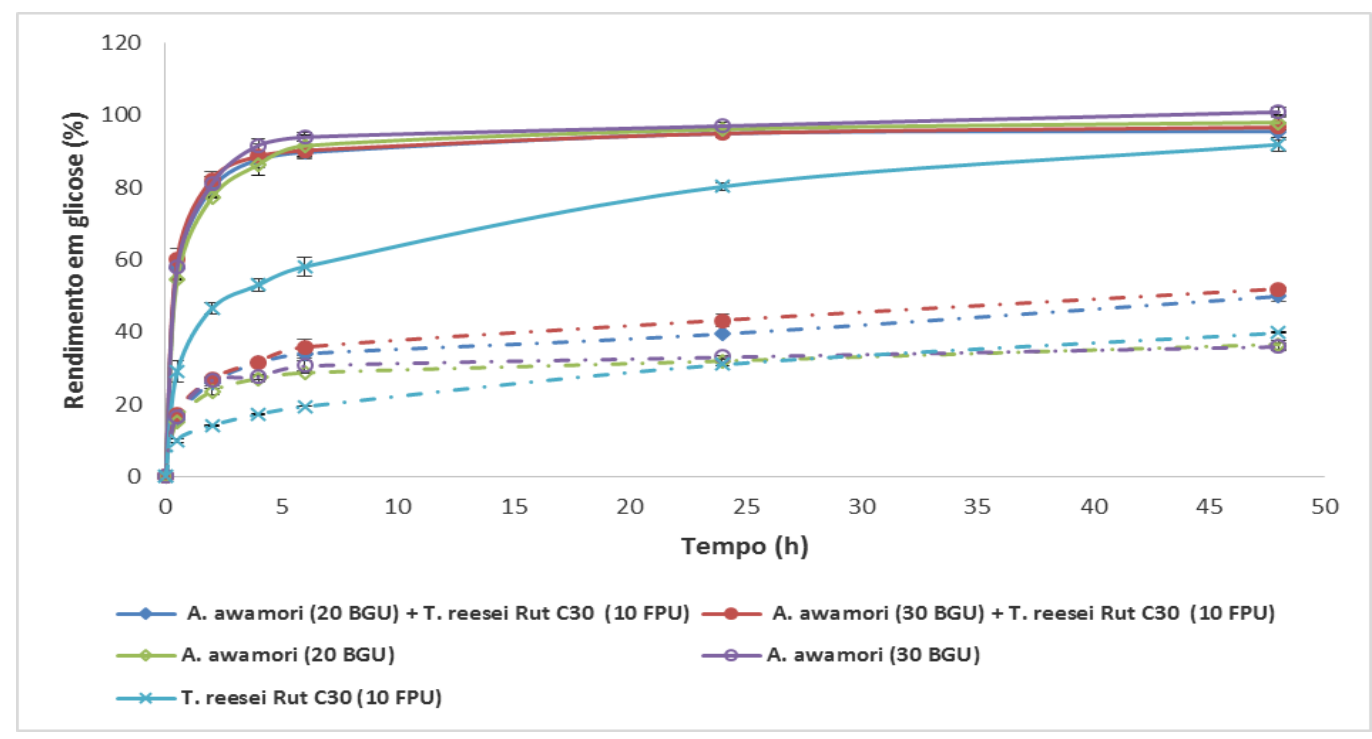

Devido à importância da presença de $\beta$-glicosidase comprovada pelos experimentos anteriores, um novo experimento, comparando a eficiência das enzimas produzidas pelos fungos $T$. reesei RUT C30 e $T$. harzianum 422, foi realizado com a biomassa íntegra. O fungo $T$. harzianum 422, além de bom produtor de celulases, é também capaz de produzir $\beta$ glicosidases em quantidade mais expressiva do que o T. reesei RUT C30.

Figura 2 - Rendimento em glicose da hidrólise da microalga íntegra utilizando as enzimas dos fungos $T$. reesei RUT C30, T. harzianum 422 e A. awamori.

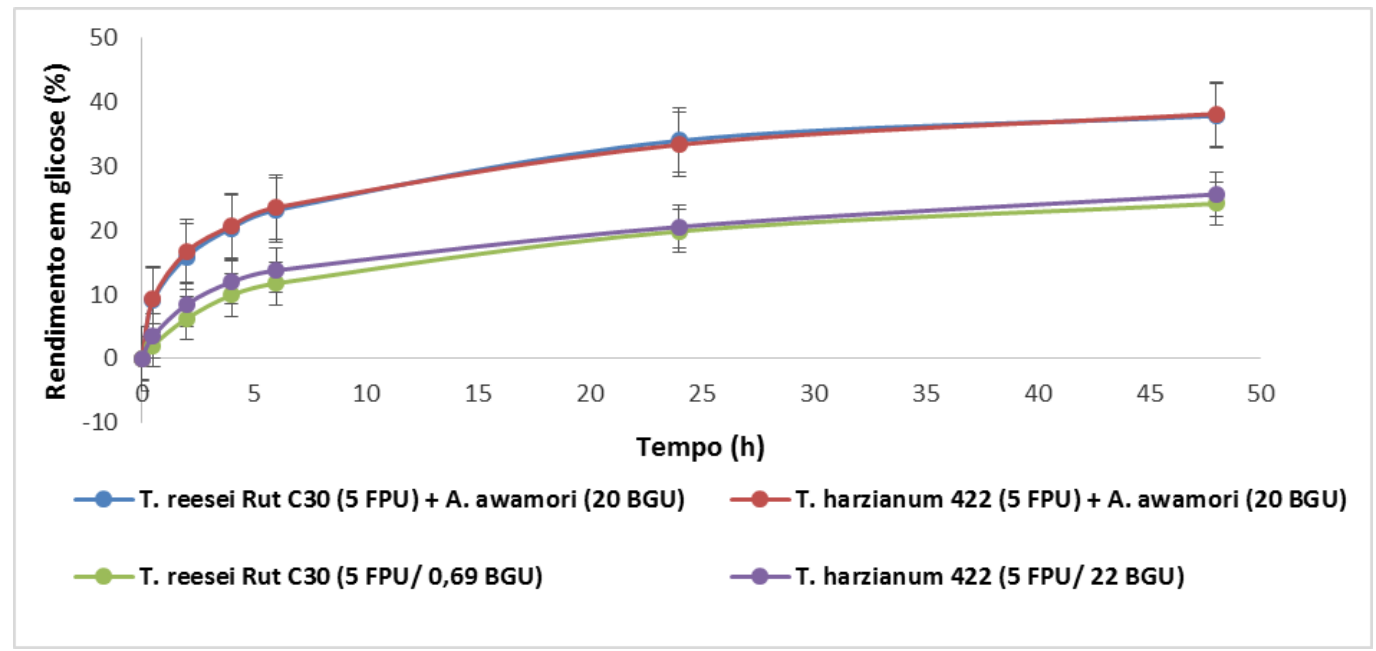

Conforme mostra a Figura 2, a presença das enzimas de $A$. awamori é importante para a hidrólise da biomassa íntegra, gerando um aumento maior que $10 \%$ no rendimento de hidrólise enzimática quanto comparado à hidrólise utilizando as enzimas separadamente. As enzimas dos fungos $T$. reesei RUT C30 e $T$. harzianum 422 não geraram diferença nos 
rendimentos de hidrólise entre si, apesar da maior carga de $\beta$-glicosidase no preparado do $T$. harzianum. Esse resultado leva a crer que a $\beta$-glicosidase produzida por $A$. awamori possui maior afinidade pelo material da microalga, sendo importante na hidrólise do mesmo.

Para testar essa hipótese, foi realizado um experimento comparando os diferentes perfis enzimáticos obtidos padronizando-se as cargas de $\beta$-glicosidase produzidas por $T$. harzianum e por A. awamori. A Figura 3 apresenta os rendimentos de glicose obtidos com preparados de A. awamori e de T. harzianum.

Figura 3 - Rendimento em glicose da hidrólise da microalga íntegra utilizando as enzimas dos fungos T. harzianum 422 e A. awamori.

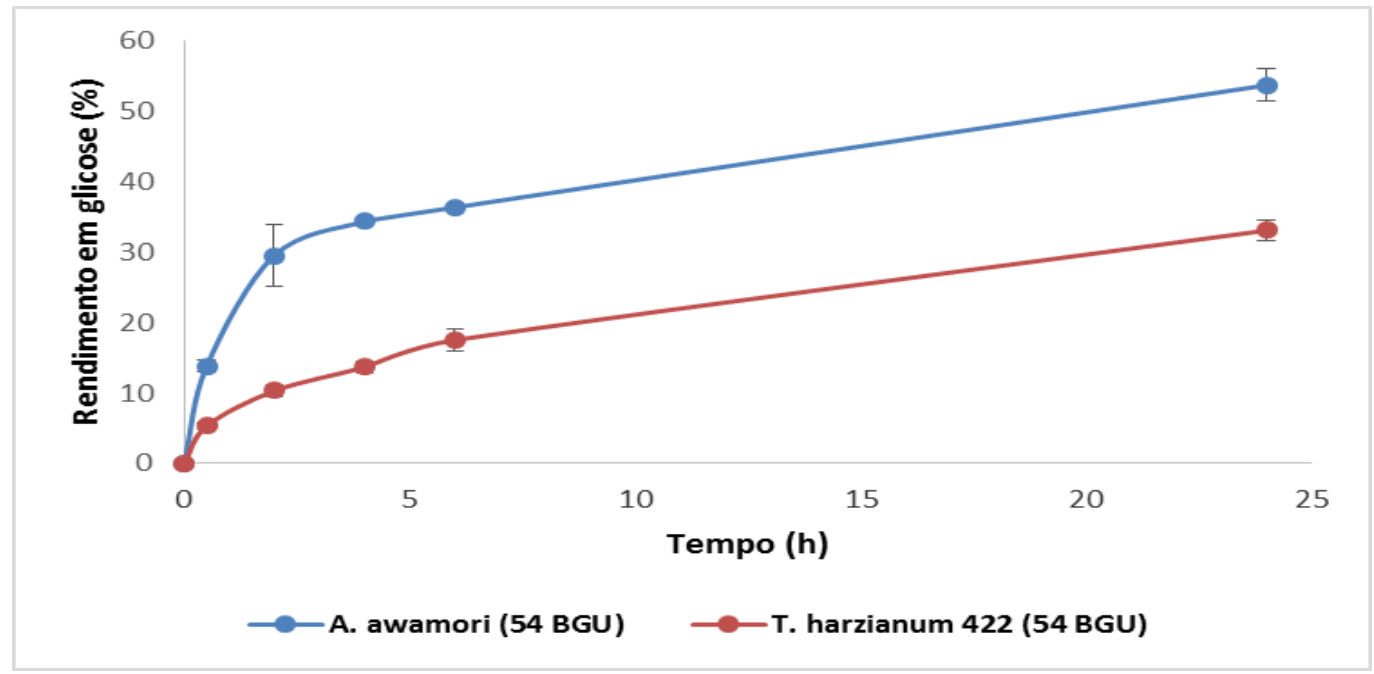

O rendimento em glicose utilizando o sobrenadante do cultivo de A. awamori foi maior ao obtido com o T. harzianum 422. Esses resultados indicam que a $\beta$-glicosidase de $A$. awamori é a mais indicada para a hidrólise da biomassa algal.

\section{CONCLUSÕES}

Através dos resultados podemos concluir que o pré-tratamento em moinho de bolas é eficiente para a biomassa algal, aumentando significativamente o rendimento da hidrólise enzimática.

A presença de exoglucanases para ser desnecessária para a hidrólise da microalga, uma vez que o preparado de A. awamori foi capaz de hidrolisar a biomassa moída e apresentou apenas uma pequena redução no rendimento final na hidrólise da biomassa íntegra. $\mathrm{O}$ preparado enzimático de Aspergillus awamori foi mais eficiente na hidrólise da microalga do que o preparado produzido por T. harzianum $422 \mathrm{em}$ condições de mesma carga de $\beta$ glicosidase. 


\section{REFERENCIAS}

NORTHCOTE, D.H., GOULDING, K.J., HORNE, R.W. The Chemical Composition and Structure of the Cell Wall of Chlorella pyrenoidosa. Biochemical Journal, 70 (3), 391-397. 1958.

POWELL, E.E., HILL, G.A. Economic assessment of an integrated bioethanol-biodieselmicroalgal fuel cell facility utilizing yeast and photosynthetic algae. Chemical Engineering Research and Design, 87, 1340-1348. 2009.

SHEEHAN, J. Engineering direct conversion of CO2 to biofuel. Nature Biotechnology, 27, 1128-1129. 2009.

SPOLAORE, P., JOANISS-CASSAN, C., DURAN, E., ISAMBERT, A. Commercial Applications of Microalgae Journal of Bioscience and Bioengineering 101(2), 87-96. 2006.

VAN WYCHEN, S., LAURENS, L.M.L. Determination of Total Carbohydrates in Algal Biomass. Laboratory Analytical Procedure, NREL/TP-5100-60957. 2013. 